\title{
Femoral venous catheter: intraperitoneal placement
}

\author{
Yasemin Piskinel $^{1} \bowtie$, Mehmet Sahap ${ }^{2} \bowtie$, Cemile Altın Balci $\square$, \\ Handan Gulec $^{4} \otimes$ Ezgi Erkilic $^{5} \otimes$, Abdulkadir But ${ }^{6}$ \\ Authors'affiliations: \\ 1- $\quad$ OORCID:0000000300113489\}, Ankara Yildirim Beyazit University, Kizilca Mahallesi, 06760 Çubuk, Ankara, Turkey. \\ 2- $\quad$ \{ORCID:0000-0003-3390-9336\}, Ankara Yildirim Beyazit University, Kizilca Mahallesi, 06760 Çubuk, Ankara, Turkey. \\ 3- Ankara Yildirim Beyazit University, Kizilca Mahallesi, 06760 Çubuk, Ankara, Turkey. \\ 4- $\quad$ OORCID:0000-0002-3547-9336\}, Ankara Yildirim Beyazit University, Kizilca Mahallesi, 06760 Çubuk, Ankara, Turkey. \\ 5- $\quad$ Ankara City Hospital, Üniversiteler, Bilkent Blv. No:1, 06800 Çankaya/Ankara, Turkey. \\ 6- Ankara Yildirim Beyazit University, Kizilca Mahallesi, 06760 Çubuk, Ankara, Turkey.
}

Correspondence: Handan Güleç; E-mail: handandrhandan@yahoo.com.tr; Phone: +90 5056725948

\section{Abstract}

Central venous cannulation through femoral veins is known to be associated with various complications. Early complications include extravasation and collection of blood, fluid, and/or contrast material in the retroperitoneal spaces or the peritoneal cavity, whereas late complications include abdominal compartment syndrome (ACS).

A 30-year-old patient was admitted to the emergency department and brought into the operating room with a preliminary diagnosis of pelvic fracture and acute abdomen. An intravenous catheter was placed into the peripheral vein and a central venous catheter in the femoral vein, in the emergency room through which blood was transfused. At the start of the operation, it was found that intraperitoneal bleeding was caused by a perforation associated with the femoral catheter.

We conclude that in the case of acute abdomen, if the femoral venous catheter was already placed in the emergency room, proper placement should be confirmed with ultrasound imaging.

Key words: Central venous catheterization; Femoral vein; Complications; Acute abdomen; Ultrasound imaging; Emergency care

Citation: Piskinel Y, Sahap M, Balci CA, Gulec H, Erkilic E, But A. Femoral venous catheter: intraperitoneal placement. Anaesth. pain intensive care 2021;25(2):203-205. DOI: 10.35975/apic.v25i2.1466

Received: 23 November 2020. Reviewed: 10 February 2021, Accepted: 1 February 2021

\section{Introduction}

Central venous cannulation (CVC) is an invasive procedure commonly used in the treatment of patients in intensive care units and in the monitoring as well as management of surgical patients. Internal jugular vein (IJV), subclavian vein (SV), and femoral vein are frequently used for this purpose. Although CVC is most commonly performed using the Seldinger technique, ultrasound guidance is now routinely being used in clinical practice at good centers. CVC is associated with various complications. Significant factors in the development of complications include anatomical structure, the experience of the operator, and the quality of the materials being. ${ }^{1-3}$ Mechanical complications are observed in 5\%-19\% of all CVC applications, infections in 5\%-26\%, and thromboembolic complications in 2\%-26\%. ${ }^{4}$ Improper placement or malposition of the CVC is very rare and 
associated with early and late complications. Early complications of femoral catheters include extravasation and collection of blood, fluid, and/or contrast material in the retroperitoneal spaces or the peritoneal cavity, whereas late complications include abdominal compartment syndrome (ACS). ${ }^{5}$

This case report aims to present a case of acute abdomen that developed due to an unrecognized venous perforation during CVC insertion and the subsequent intraperitoneal hemorrhage.

\section{Case report}

A 30-year-old female patient was admitted to the emergency department following a car accident and brought into the operating room with a preliminary diagnosis of pelvic fracture and acute abdomen.The femoral catheter was opened by the emergency service. we know it shouldn't be stuck. She was lethargic. Her arterial blood pressure (ABP) was $85 / 50$ $\mathrm{mmHg}$, apical pulse was $140 \mathrm{bpm}$, and peripheral oxygen saturation $\left(\mathrm{SpO}_{2}\right)$ was $99 \%$. There was ecchymosis in the left eye and the extremities, and rales and rhonchi were audible on chest auscultation.

The patient was evaluated as ASA I-E. She was moved to the operating table and monitored. A CVC $18 \mathrm{G}$ had been placed into her femoral vein and a $20 \mathrm{G}$ catheter in a peripheral vein in the emergency room and the patient was being transfused through the central venous catheter.

Through the femoral CVC, we infused propofol 70 $\mathrm{mg}$, ketamine $30 \mathrm{mg}$, rocuronium $40 \mathrm{mg}$, and lidocaine $60 \mathrm{mg}$ for anesthesia induction; however, anesthesia could not be induced, suggesting that the catheter was malpositioned. Subsequently, we administered propofol $30 \mathrm{mg}$ and rocuronium 30 mg through the peripheral vein catheter and performed endotracheal intubation with a $7.0 \mathrm{~mm}$ endotracheal tube (ETT) without complications. Anesthesia was maintained with $1 \%-2 \%$ sevoflurane in a 50/50 $\mathrm{O}_{2} /$ air mixture. Arterial blood pressure was invasively monitored with left radial artery cannulation.

At the start of the operation, it was confirmed that intraperitoneal bleeding was in fact caused by a perforation associated with the femoral catheter. The femoral vein was repaired by the cardiovascular surgeon and the patient was administered 4 units of red cell concentrate (RCC), 2 units of FFP, $500 \mathrm{ml}$ colloid, and $1 \mathrm{~L}$ crystalloid solution. Since the femoral catheter was placed intra-abdominally, the blood as well as the induction agents had been given intra-abdominally rather than intravenously. Preoperative $\mathrm{Hb}$ was 6.6 $\mathrm{mg} / \mathrm{dL}$. After 2 units RCC transfusion $\mathrm{Hb}$ was 7.2 $\mathrm{mg} / \mathrm{dL}$. So, we continued transfusion. This case required urgent intervention, so we induced rapid sequence general anesthesia to the patient. Intraoperative hemodynamics were not stable. The patient was hypotensive. Arterial blood gas analysis showed acidosis, $\mathrm{pH}$ was 7.22 and base deficit was minus 12. We kept the patient intubated for postoperative period, and transferred her to the ICU without any further complications. Despite expert management in ICU, the patient could not be saved and she expired within the first 24 hours postoperatively.

\section{Discussion}

CVCs should be inserted carefully for effective use and to avoid potential complications. Malpositioning can lead to several complications such as hemothorax, pneumothorax, cardiac arrhythmia, endocarditis, thromboembolism, vascular perforations, air embolism, and nerve injuries. Factors associated with catheter malposition are an inexperienced practitioner, repeat cannulation of a previously cannulated vein, a history of surgery at the site of CVC, a history of radiotherapy, advanced age, and obesity. ${ }^{6,7} \mathrm{CVCs}$ are frequently used in emergency situations, especially for large amounts of and rapid fluid and blood transfusions.

In order to improve CVC insertion procedure and to reduce complications, it is necessary to have a comprehensive knowledge of the structural anatomy of the area. ${ }^{8}$

Mechanical vascular complications commonly occur due to the careless use of puncture needles, guidewires, and dilators. Risk factors include misdirection of the puncture needle, the orientation of the guidewire before the aspiration of blood, bending of the wire, multiple cannulation attempts, severe dehydration, morbid obesity, and coagulopathies. ${ }^{9}$ In our patient, a femoral catheter was placed in the emergency room for rapid fluid and blood replacement, and it is not known if there were multiple cannulation attempts or whether it was inserted by an experienced practitioner. Failure to induce general anesthesia in our patient, despite 
injecting adequate amounts of anesthetic agents, alarmed us to the possibility of the extravasation of the drugs as well as the transfused blood.

Ultrasound guidance can facilitate the proper placement of a femoral venous catheter. Using ultrasonography for cannulation requires skill and knowledge, but in skilled hands it also needs equipment and time. ${ }^{10}$ Anesthesiologists are known to have sufficient skills to rapidly cannulate a femoral vein in an emergency, but this may not be the case for other physicians. In our patient, the central catheter had been inserted in the emergency room before they were brought into the operating room.

Femoral venous catheterization complications are usually associated with infection and thrombosis. ${ }^{5}$ Retroperitoneal hemorrhage is a significant lifethreatening complication. Therefore, an inappropriate technique in femoral vein catheterization can lead to arterial puncture, severe bleeding, and dangerous complications. ${ }^{11}$ In our patient, the dissection of the femoral vein caused the transfused blood products to collect in the intraperitoneal space and led to the development of an acute abdomen picture.

We conclude that all CVC insertions must be tried under ultrasound guidance. If the facility is not available, the fluoroscope and image intensifiers might be used. A few ml of contrast will indicate the correct placement or otherwise. In any case proper placement must be confirmed as early as possible.

\section{Conflict of interests}

No conflict declared by the authors

\section{Authors contribution}

All authors participated in the management of the case as well s preparation of the manuscript.

\section{References}

1. Batra RK, Guleria S, Mandal S. Unusual complication of internal jugular vein cannulation. Indian J Chest Dis Allied Sci. 2002;44:137-9. [PubMed]
2. Morgan GE Jr, Mikhail MS, Murray MJ. Patient monitors. In: Morgan GE Jr, Mikhail MS, Murray MJ, (eds.) Clinical anesthesiology. 4th ed. New York: McGraw-Hill Companies Inc; 2006 p.100-2.

3. Paw HG. Bilateral pleural effusions: unexpected complication after left internal jugular venous catheterization for total parenteral nutrition. $\mathrm{Br} \mathrm{J}$ Anaesth. 2002;89:647-50. [PubMed] DOI: 10.1093/bja/aef224

4. Eisen LA, Narasimhan M, Berger JS, Mayo PH, Rosen MJ, Schneider RF. Mechanical complications of central venous catheters. J Intensive Care Med. 2006;21:40-6. [PubMed] DOI: $10.1177 / 0885066605280884$

5. Pafitanis G, Spyridon K, Theodorakopoulou E, Mason K, Ygropoulou O, Mousafiri O. A case report of abdominal compartment syndrome caused by malposition of a femoral venous catheter. Int J Surg Case Rep. 2015;12:84-6. [PubMed] DOI: 10.1016/j.ijscr.2015.05.002

6. Dariushnia SR, Wallace MJ, Siddiqi NH, Towbin RB, Wojak JC, Kundu S, et al. Quality improvement guidelines for central venousaccess. J Vasc Interv Radiol. 2010;21:976-81. [PubMed] DOI: 10.1016/j.jvir.2010.03.006

7. McGee DC, Gould MK. Preventing complications of central venous catheterization. N Engl J Med. $2003 \mathrm{Mar}$ 20;348(12):1123-33. [PubMed] DOI: 10.1056/NEJMra011883

8. Duntley P, Siever J, Korwes ML, Harpel K, Heffner JE. Vascular erosion by central venous catheters. Clinical features and outcome. Chest. 1992;101(6):1633-8. [PubMed] DOI: 10.1378/chest.101.6.1633

9. Schummer W, Schummer C, Fröber R. Internal jugular vein and anatomic relationship at the root of the neck. Anesth Analg. 2003:96(5):1540. [PubMed] DOI: 10.1213/01.ane.0000072448.11064.d8

10. Brass P, Hellmich M, Kolodziej L, Schick G, Smith AF. Ultrasound guidance versus anatomical landmarks for subclavian or femoral vein catheterization. Cochrane Database Syst Rev. 2015 Jan 9;1(1):CD011447. [PubMed] DOI: 10.1002/14651858.CD011447

11. Akata T, Nakayama $T$, Kandabashi T, Kodama K, Takahashi S. Massive retroperitoneal hemorrhage associated with femoral vein cannulation. J Clin Anesth. 1998;10(4):321-6. [PubMed] DOI: 10.1016/s09528180(98)00036-1 